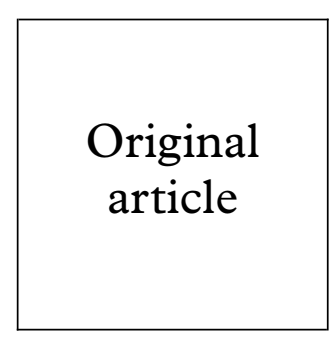

\title{
The tampon test for trichomoniasis: a comparison between conventional methods and a polymerase chain reaction for Trichomonas vaginalis in women
}

\author{
B A Paterson, S N Tabrizi, S M Garland, C K Fairley, F J Bowden
}

\begin{abstract}
Objectives: Trichomonas vaginalis is the most common STD worldwide and the infection has been linked with an increased risk of HIV transmission. We present a detailed comparison between conventional collection and testing methods and the polymerase chain reaction (PCR) tampon test for $T$ vaginalis.

Methods: Women were tested for the presence of $T$ vaginalis by PCR analysis of a tampon specimen and by conventional methods which included one or more of the following: culture and microscopy from a high vaginal swab (HVS) or endocervical swab (ECS), and microscopy of a Papanicolaou (Pap) smear.

Results: T vaginalis was detected in 51/590 (8.6\%) conventional tests and 93/590 (15.8\%) tampon specimens. Retesting of all tampon PCR positive specimens confirmed 89/93 (95.7\%) tests. Using the tampon PCR as the reference, the sensitivities of the different conventional sampling and testing methods for the detection of $T$ vaginalis were $8.3 \%(5 / 60)$ for ECS microscopy or culture, $31 \%$ (13/42) for HVS microscopy or culture, $52.8 \%(19 / 36)$ for HVS directly inoculated into Trichomonas medium and 59.4\% (38/64) for Pap smear.

Conclusions: No conventional test in the remote setting has comparable sensitivity to PCR. The Pap smear is the next most sensitive, but requires a speculum examination. The use of PCR will allow inclusion of $T$ vaginalis into STD screening programmes in both developed (lower prevalence) and developing (higher prevalence) countries.
\end{abstract}

(Sex Transm Inf 1998;74:136-139)

Keywords: tampons; Trichomonas vaginalis; polymerase chain reaction

\section{Introduction}

Improved treatment of sexually transmitted diseases (STDs) reduces the transmission of human immunodeficiency virus (HIV) ${ }^{1}$ infection. Trichomonas vaginalis is the most common STD worldwide and affects an estimated 170 million people annually. ${ }^{2}$ Because this infection is so common and has been linked with an increased risk of HIV transmission, ${ }^{3}$ reduction in its prevalence should be a focus of strategies to reduce HIV infection.

STDs are often asymptomatic or cause only minor symptoms; therefore, identification and treatment of asymptomatic infection is essential for effective STD control. This is often hampered by the lack of a simple, quick, and non-invasive screening test. The currently available tests for $T$ vaginalis may lack sensitivity when they are subjected to long transport times, especially when climatic conditions are extreme. We have shown that a self administered tampon method of specimen collection tested by polymerase chain reaction (PCR) for Chlamydia trachomatis, Neisseria gonorrhoeae, and $T$ vaginalis to be a highly acceptable and reliable screening tool. ${ }^{4}$ We now present a detailed comparison between conventional collection and sampling methods and the PCR tampon test for $T$ vaginalis.

\section{Methods}

In our initial study, detailed records of the different conventional techniques used for the detection of $T$ vaginalis were collected, but not reported. ${ }^{4}$ We have included results from an additional 110 patients recruited to our original study.

The study was conducted between July 1995 and July 1996 in sexual health and family planning clinics in urban areas and community health centres in the rural and remote areas of the top end of the Northern Territory of Australia. The local ethics committee granted approval for the study (95/19, May 1995). Women attending for an STD check up, a Papanicolaou (Pap) smear, or for treatment of symptomatic disease were asked to give written informed consent and complete a brief questionnaire.

Each woman was asked to perform the "tampon test" in private by inserting and immediately removing a tampon and placing it in PCR transport medium $(0.14 \mathrm{M} \mathrm{NaCl}, 3$ $\left.\mathrm{mM} \mathrm{KCl}, 10 \mathrm{mM} \mathrm{Na} \mathrm{HPO}_{4}, 2 \mathrm{mM} \mathrm{KH_{2 }} \mathrm{PO}_{4}\right)^{4}$ This was followed by a speculum examination for collection of swabs and Pap smear (if due). Tampon specimens arrived at the Melbourne laboratory a median of 7 days (range 1-26 days) after collection and travelling some 2500 $\mathrm{km}$. There were delays of up to 5 days in the conventional specimens reaching one of three Northern Territory laboratories several hundred kilometres away.

The tampon specimen was prepared for testing by squeezing the tampon to dislodge the cells followed by centrifugation to form a cell pellet. $^{5}$ The DNA was extracted from the $20 \mu \mathrm{l}$ aliquot of tampon cell pellet using the QIAamp 


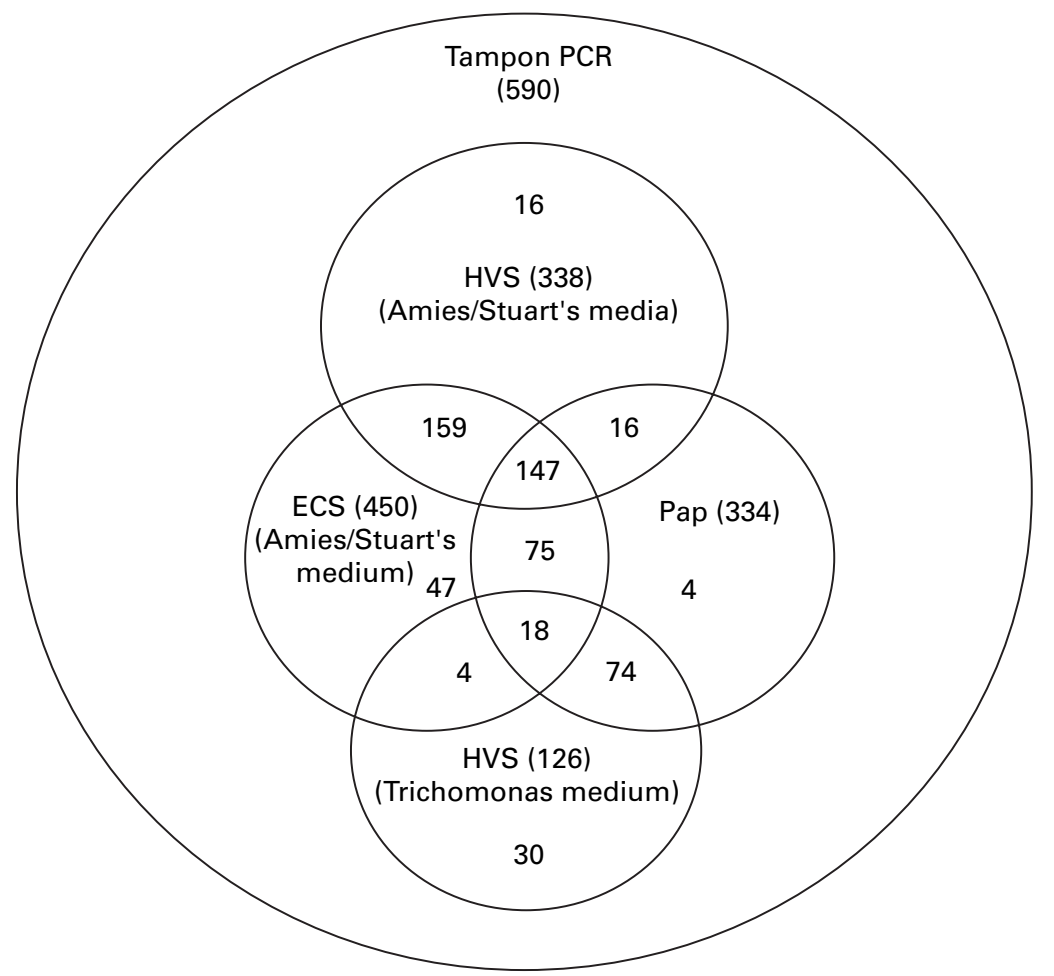

Figure 1 Conventional methods of detection for Trichomonas vaginalis. ECS = endocervical swab; HVS =high vaginal swab; Pap=Papanicolaou smear. ( ) =total number of tests.

DNA Purification Kit (Qiagen Inc, Chastsworth, CA, USA) following the manufacturer's instructions.

PCR reactions consisted of $20 \mu$ aliquot of extracted DNA (that is, $1 / 10$ of the total eluted DNA), 50 pmol of each primer TVA5-TVA6, directed at amplifying a $102 \mathrm{bp}$ fragment of genomic DNA, $60 \mathrm{mM} \mathrm{KCl}, 10 \mathrm{mM}$ TRIS $\mathrm{pH} 8.3,1.5 \mathrm{mM} \mathrm{MgCl}_{2}, 200 \mu \mathrm{M}$ of each of dATP, dGTP, and dCTP, and $190 \mu \mathrm{M}$ dTTP, $10 \mu \mathrm{M}$ digoxigenin-dUTP, and 2.5 units of the heat stable Thermus aquaticus (Taq) polymerase (Boehringer Mannheim, Mannheim, Germany) in a total of $50 \mu \mathrm{l}$. Each reaction was amplified 35 cycles using variables of $94^{\circ} \mathrm{C}$ for 1 minute, $47^{\circ} \mathrm{C}$ for 1 minute, and $67^{\circ} \mathrm{C}$ for 1 minute. Before the first cycle, reactions were heated for 5 minutes at $94^{\circ} \mathrm{C}$ and an additional 10 minutes was included at the final $67^{\circ} \mathrm{C}$ elongation cycle. An additional aliquot of DNA was amplified using $5 \mathrm{pmol}$ of each of the $\beta$ globin primers GH20-PC04. ${ }^{7}$ This reaction served as a positive internal control which simultaneously amplifies a human $\beta$ globin product of $260 \mathrm{bp}$. Generation of an amplicon by this primer indicated presence of adequate amplifiable DNA.

Positive clinical specimens by culture, were used as positive controls. Specimen contamination and carryover are prevented by using positive displacement pipettes, prior aliquoting of all reagents, and performing pre- and postPCR steps in different rooms specifically allocated for PCR.

PCR reactions for detection of $T$ vaginalis and $\beta$ globin sequences were hybridised and detected by the Enzymun-Test DNA detection assay (Boehringer Mannheim) using the automated ES 300 analyser following the manufac-
Table 1 Reasons for STD testing

\begin{tabular}{lll}
\hline Reason for test & Number & $\%$ \\
\hline Symptoms of an STD & 61 & 10.3 \\
Contact of an STD & 30 & 5.1 \\
$\begin{array}{l}\text { Pap smear due } \\
\text { "Well women's check" }\end{array}$ & 195 & 33.1 \\
$\quad$ & & \\
$\quad$ Pap not due) & 26 & 4.4 \\
Antenatal check & 9 & 1.5 \\
Request for STD check & 241 & 40.9 \\
Other & 16 & 2.7 \\
Unknown & 12 & 1.0 \\
Total & 590 & 100 \\
\hline
\end{tabular}

turer's protocol. The oligonucleotide probe $\mathrm{PC}^{7} 3^{7}$ was used for detection of $\beta$ globin sequences. The oligonucleotide probe TVB (5'-GACCTCTAGAAGAAGACTCAG-3') was designed from the nested amplification area $^{6}$ and was used for detection of $T$ vaginalis sequences. All $T$ vaginalis positive samples by conventional test or tampon PCR were tested by amplification using a second primer pair and subsequent hybridisation as described by Kengne $e t a l .^{8}$

A conventional test for $T$ vaginalis was at least one of the following: Pap smear or high vaginal swab (HVS) or endocervical swab (ECS) transported in either Amies medium or Stuart's medium. One laboratory went on to culture the HVS (or the ECS if an HVS was not taken) using Trichomonas medium (Oxoid, based on Feinberg Whittington medium) read daily for 2 days provided the swab arrived in the laboratory within 48 hours. If a dry slide was also received a Gram stain was performed. The other two laboratories performed microscopy of a wet preparation and Gram stain if a dry slide was received. Wet preparations were not performed in the health centres. The result from the endocervical swabs was included because several remote health centres did not routinely perform an HVS as part of an STD screen. In a subset of women attending remote communities, an HVS was taken and directly inoculated into Trichomonas medium (Oxoid, based on Feinberg Whittington medium) in an attempt to improve the yield.

STATISTICAL ANALYSIS

A $\chi^{2}$ test or Fisher's exact test was used to assess unpaired categorical variables. A $\mathrm{McNe}-$ mar test was used for paired categorical variables. Confidence intervals were calculated using the software package "Confidence interval analysis". ' Student's $t$ test was used to calculate the difference between means.

\section{Results}

The conventional testing methods undertaken on specimens from the 590 women who had performed the tampon test are illustrated in figure 1. Of the 590 women tested, 493 $(83.6 \%)$ had two or more conventional tests performed. The mean age was 28 years (range 13-73 years).

The reasons for testing for STD are shown in table 1.

$T$ vaginalis was detected in $51 / 590(8.6 \%)$ conventional tests and 93/590 (15.8\%) tampon specimens, $(\mathrm{p}<<0.001)$ (table 2). Retesting of all positive tampon PCR specimens confirmed 
Table 2 Detection of Trichomonas vaginalis - tampon PCR versus conventional test

\begin{tabular}{llll}
\hline \multirow{2}{*}{$\begin{array}{l}\text { Conventional } \\
\text { test }{ }^{\star}\end{array}$} & \multicolumn{2}{l}{ Tampon PCR } & \\
\cline { 2 - 3 } & Positive & Negative & Total \\
\hline Positive & 51 & 4 & 55 \\
Negative & 42 & 493 & 435 \\
Total & 93 & 497 & 590 \\
\hline
\end{tabular}

$\mathrm{p}<0.001$ (McNemar test)

$\star$ At least one of Pap smear or high vaginal swab or an endocervical swab for culture or microscopy of a wet preparation.

Table 3 Detection of Trichomonas vaginalis - high vaginal swab (HVS) versus Pap smear

\begin{tabular}{llll}
\hline & \multicolumn{2}{l}{ Pap smear } & \\
\cline { 2 - 3 } HVS & $\begin{array}{l}\text { Trichomonas } \\
\text { positive }\end{array}$ & $\begin{array}{c}\text { Trichomonas } \\
\text { negative }\end{array}$ & Total \\
\hline Microscopy/ & & & \\
$\quad$ culture: & & 1 & 6 \\
$\begin{array}{l}\text { Positive } \\
\text { Negative }\end{array}$ & 5 & 150 & 157 \\
Total & 12 & 151 & 163 \\
Directly trich & & & $\mathrm{p}=0.08$ \\
medium: & & & \\
$\begin{array}{l}\text { Positive } \\
\text { Negative }\end{array}$ & 15 & 3 & 18 \\
Total & 23 & 66 & 74 \\
& & 70 & 92 \\
& & & $\mathrm{p}=0.23$ \\
\hline
\end{tabular}

McNemar test.

89/93 (95.7\%) tests. A random sample of 180 tampon PCR negative specimens were all negative when retested with the second primer set. There were four cases where the tampon PCR was negative and conventional testing was positive; one was diagnosed on HVS only and three on Pap smear only. Review of these Pap smears showed features highly suggestive of the presence of $T$ vaginalis in two smears and the third was equivocal. The mean age of women with trichomoniasis diagnosed by tampon PCR was 30.2 (SD 8.9) years and for women negative by tampon PCR was 27.8 (9.48) years, $\mathrm{p}$ $<0.005$. Only $9 / 93(9.7 \%)$ of women complained of symptoms consistent with an STD.

Comparing the 163 women who had both a Pap smear and an HVS transported in Amies or Stuart's medium, the Pap smear was positive for $T$ vaginalis in $12 / 163(7.4 \%)$ versus $6 / 163$ (3.7\%) for HVS $(\mathrm{p}=0.08)$ (table 3). Comparing the 92 women who had both a Pap smear and an HVS directly inoculated into trichomonas medium, the Pap smear was positive in $23 / 92(25 \%)$ versus $18 / 92$ (19.6\%) for HVS $(\mathrm{p}=0.23)$ (table 3).

Using the tampon PCR as the reference, the sensitivities of the different conventional sampling and testing methods for the detection of $T$ vaginalis were $8.3 \%$ (5/60) for ECS microscopy or culture, $31 \%(13 / 42)$ for HVS microscopy or culture, $52.8 \%(19 / 36)$ for HVS directly inoculated into trichomonas medium and 59.4\% (38/64) for Pap smear (table 4).

\section{Discussion}

In this paper we provide a detailed comparison of the conventional methods used to diagnose $T$ vaginalis in women from urban and remote settings. The greatest sensitivity was associated with the Pap smear and the least with ECS.
Table 4 Sensitivity of the different methods compared with tampon PCR

\begin{tabular}{|c|c|c|c|}
\hline \multirow{2}{*}{$\begin{array}{l}\text { Conventional } \\
\text { methods }\end{array}$} & \multicolumn{2}{|c|}{ Tampon PCR } & \multirow[b]{2}{*}{$95 \% C I$} \\
\hline & Positive & Negative & \\
\hline \multicolumn{4}{|c|}{$\begin{array}{l}\text { ECS microscopy } \\
\text { or culture: }\end{array}$} \\
\hline Positive & 5 & 0 & \\
\hline Negative & 55 & 390 & \\
\hline Sensitivity & $8.3 \%$ & & $3-18 \%$ \\
\hline \multicolumn{4}{|c|}{$\begin{array}{l}\text { HVS microscopy } \\
\text { or culture: }\end{array}$} \\
\hline Positive & 13 & 1 & \\
\hline Negative & 29 & 295 & \\
\hline Sensitivity & $31 \%$ & & $18-47 \%$ \\
\hline \multicolumn{4}{|c|}{$\begin{array}{l}\text { HVS trichomonas } \\
\text { medium: }\end{array}$} \\
\hline Positive & 19 & 0 & \\
\hline Negative & 17 & 90 & \\
\hline Sensitivity & $52.83 \%$ & & $36-70 \%$ \\
\hline \multicolumn{4}{|l|}{ Pap smear: } \\
\hline Positive & 38 & 3 & \\
\hline Negative & 26 & 264 & \\
\hline Sensitivity & $59.4 \%$ & & $46-72 \%$ \\
\hline
\end{tabular}

However, no conventional test approached the sensitivity of the tampon specimen tested by PCR.

Poor sensitivity with culture and wet preparations is well documented. ${ }^{10-16}$ In our study transit times to the laboratory were long-in many instances specimens had to travel in high temperatures for several hundred kilometres. The Pap smear performed better than wet preparation, or culture of HVS, or direct inoculation of HVS into trichomonas medium. The Pap smear has been identified as a useful adjunct to culture for the detection of $T$ vaginalis $^{13-15}$ and reported sensitivities range form $62 \%$ to $83 \%{ }^{17}$ Our findings confirm that an ECS is not useful in diagnosing $T$ vaginalis, which not surprising as it is primarily a vaginal and not a cervical pathogen.

False positive results can occur with DNA amplification diagnoses. Repeat testing of discrepant specimens with different primer sets is an accepted method of validating DNA amplification tests although it may slightly overestimate the sensitivity and specificity. ${ }^{18}$ However, in our study, we retested all positive tampon PCR specimens for $T$ vaginalis and a random sample of tampon PCR negative specimens with a second primer set which confirmed all the negative and all but four of the positive PCR samples. Ideally, the diagnosis of $T$ vaginalis by conventional methods should have been made by direct wet preparation and immediate microscopy followed by direct inoculation into a selective trichomonas broth for culture. It would have been impossible to provide facilities, training, and staff to do this in a field study involving nearly 20 small remote health centres located hundreds of kilometres from the main centre.

There has been a renewed public health interest in STD control since STDs were shown to facilitate the transmission of HIV. The association of genital ulcerative disease with HIV transmission is well documented but the strength of association may be not be as high as originally reported. ${ }^{19}$ The link between non-ulcerative STDs and HIV transmission may be of greater public health importance given that they affect considerably more of the 
world's population. ${ }^{3}$ Several studies have shown a higher prevalence of $T$ vaginalis in HIV positive than HIV negative patients. ${ }^{20}{ }^{21}$ Despite the fact that $T$ vaginalis receives less attention in the world literature than Neisseria gonorrhoeae and Chlamydia trachomatis, it is not a benign condition. The presence of $T$ vaginalis may predispose to premature rupture of membranes, premature labour, and low birth weight $^{22}$ and its potential role in HIV transmission is of great concern. For these reasons consideration should be given to making $T$ vaginalis a notifiable disease along with $N$ gonorrhoeae and $C$ trachomatis in order to monitor control programmes.

History and clinical examination are poor predictors of infection with $T$ vaginalis ${ }^{16} 1819$ and in our study fewer than $10 \%$ of women were symptomatic. With the exception of women attending sexual health clinics for an STD check, the majority of STD screening in the top end of the Northern Territory has been opportunistic screening at the time of the 1-2 yearly well women's check and speculum examination for Pap smear. Many health centres do not routinely perform an HVS to detect $T$ vaginalis, relying on coincidental findings on Pap smear. The PCR tampon test for $C$ trachomatis, $N$ gonorrhoeae, and $T$ vaginalis is becoming the standard method for STD detection in the remote, as well as many urban centres. This will enable more frequent screening and staff already report that women are attending clinics requesting a tampon test (or " $T$ " test as it is know locally).

We have little knowledge of the natural history of $T$ vaginalis in this population and the prevalence in men is unknown. A study using PCR for $T$ vaginalis from a first void urine specimen in men is planned.

In conclusion, $T$ vaginalis is the most common STD and is often asymptomatic so HIV control strategies will need to focus on simple, quick, acceptable, and sensitive methods for its detection. No conventional test in the remote setting has comparable sensitivity to PCR; Pap smear is about $60 \%$ but requires vaginal examination. The use of this PCR will allow inclusion of $T$ vaginalis into STD screening programmes in both developed (lower prevalence) and developing (higher prevalence) countries.

This project was supported by a Commonwealth AIDS Research Grant (CARG). We thank April Bright, Albert Lowe Research Grant (CARG). We thank April Bright, Albert Lowe,
Jacki Mein, Sue Dubow, Lauren Hutton, Family Planning NT,
Western Pathology, QML Pathology, Royal Darwin Hospital Pathology, and numerous staff members of Territory Health Services together with Shujun Chen and Anthony Borg from the Royal Women's Hospital (RWH). SNT receives support from Division of Pathology (RWH), Research and Education fund and CARG.

1 Grosskurth $\mathrm{H}$, Mosha F, Todd J, et al. Impact of improved treatment of sexually transmitted diseases on HIV infection in rural Tanzania: randomised controlled trial. Lancet 1995;346:530-6.

2 WHO. Global prevalence and incidence of selected curable sexually transmitted diseases: overview and estimates. Geneva: World Health Organisation, 1995.

3 Laga M, Manoka A, Kivuvu $M$, et al. Non-ulcerative sexually transmitted diseases as risk factors for HIV-1 transmission in women: results from a cohort study. AIDS 1993;7:95-102.

4 Tabrizi SN, Paterson B, Fairley CK, Bowden FJ, Garland SM. A self-administered technique for the detection of sexually transmitted diseases in remote communities. $f$ Infect Dis 1997;1:289-92.

5 Fairley CK, Chen S, Tabrizi SN, et al. A novel method for the assessment of human papillomavirus infection. F Infect Dis 1992;165:1103-6.

6 Riley DE, Roberts MC, Takayama T, Krieger JN. Development of a polymerase chain reaction-based diagnosis of Trichomonas vaginalis. 7 Clin Microbiol 1992;30:465-72.

7 Resnick RM, Cornelissen MT, Wright DK, et al. Detection and typing of human papillomavirus in archival cervical and typing of human papilomavirus in archival cervical cancer specimens by DNA amplification with

primers. F Natl Cancer Inst 1990;82:1477-84.
8 Kengne P, Veas F, Vidal N, Rey J, Cuny G. Trichomonas vaginalis: repeated DNA target for highly sensitive and spevaginalis: repeated DNA target for highly sensitive and spe-
cific polymerase chain reaction diagnosis. Cell and $M o$ cific polymerase chain
Probes 1994;40:819-31.

9 Morris JA, Gardner MJ. Calculating confidence intervals for relative risks, odds ratios and standardised ratios and rates. In: Gardner MJ, Altman DG, eds. Statistics with confidence. London: BMJ Publications, 1990:50-63.

10 Petersen CS, Carl L, Alnor D, Thomsen U, Thomsen HK. Ignored trichomonal infestation diagnosed by Papanicolaou smear. Genitourin Med 1995;71:257-8.

11 Harry TC, Rashid S, Saravanamuttu KM, Shrestha TL. Ignored trichomonal infestation diagnosed by Papanicoloou smear (letter). Genitourin Med 1995;71:257-8.

12 Gelbart SM, Thomason JL, Osypowski PJ, et al. Growth of Trichomonas vaginalis in commercial culture media. f Clin Trichomonas vaginalis in

13 Wolner-Hanssen Krieger JN, Stevens CE, Kiviat NB, et al. Wlinical manifestations of vaginal trichomoniasis. $\mathscr{f} A M A$ 1989;261:571-6.

14 Krieger JN, Tam MR, Stevens CE, et al. Diagnosis of trichomoniasis. FAMA 1988;259:1223-7.

15 Spence MR, Hollander DH, Smith J, et al. The clinical and laboratory diagnosis of Trichomonas vaginalis infection. Sex Transm Dis 1980;7:168-71.

16 Fouts C, Kraus SJ. Trichomonas vaginalis: reevaluation of its clinical presentation and laboratory diagnosis. F Infect Dis 1980;142:137-43.

17 Zang ZF. Epidemiology of Trichomonas vaginalis a prospective study in China. Sex Transm Dis 1996;23:41524 .

18 Hadgu A. The discrepancy in discrepant analysis. Lancet 1996;348:592-3.

19 Dickerson MC, Johnston J, Delea Msia TE, White A, Andrews E. The causal role for genital ulcer disease as a risk factor for transmission of human immunodeficiency virus, an application of the Bradford Hill criteria. Sex Transm Dis 1996;23:429-40.

20 Leroy V, De Clercq A, Ladner J, et al. Should screening of genital infections be part of antenatal care in areas of high HIV prevalence? Genitourin Med 1995;71:207-11.

21 Ghys PD, Diallo MO, Ettiegne Traore V, et al. Genital ulcers associated with human mmunodeficiency virus-related immunosuppression in female sex workers in Abidjan, Ivory Coast. F Infect Dis 1995;172:1371-4.

22 Gibbs RS, Romero R, Hillier SL, Eschenbach DA, Sweet RL. A review of premature birth and subclinical infection. Am f Obstet Gynecol 1992;166:1515-28. 